\title{
Dopamine Autoxidation Is Controlled by Acidic pH
}

\author{
Nejc Umek ${ }^{1,2}$, Blaž Geršak ${ }^{1}$, Neli Vintar ${ }^{1,3}$, Maja Šoštarič ${ }^{1,3}$ and Janez Mavri ${ }^{* *}$ \\ ${ }^{1}$ Department of Anesthesiology and Surgical Intensive Therapy, University Medical Centre Ljubljana, Ljubljana, Slovenia, \\ ${ }^{2}$ Institute of Anatomy, Faculty of Medicine, University of Ljubljana, Ljubljana, Slovenia, ${ }^{3}$ Department of Anesthesiology and \\ Reanimatology, Faculty of Medicine, University of Ljubljana, Ljubljana, Slovenia, ${ }^{4}$ National Institute of Chemistry, Ljubljana, \\ Slovenia
}

OPEN ACCESS

Edited by:

Karsten Hiller,

Technische Universitat Braunschweig,

Germany

Reviewed by:

Dietmar Fuchs,

Innsbruck Medical University, Austria

Stefan Schulz,

Technische Universitat Braunschweig,

Germany

*Correspondence:

Janez Mavri

janez.mavri@ki.si

Received: 27 August 2018 Accepted: 03 December 2018 Published: 18 December 2018

Citation:

Umek N, Geršak B, Vintar N,

Šoštarič M and Mavri J (2018)

Dopamine Autoxidation is Controlled

by Acidic $\mathrm{pH}$.

Front. Mol. Neurosci. 11:467.

doi: 10.3389/fnmol.2018.00467
We studied the reaction mechanism of dopamine autoxidation using quantum chemical methods. Unlike other biogenic amines important in the central nervous system, dopamine and noradrenaline are capable of undergoing a non-enzymatic autoxidative reaction giving rise to a superoxide anion that further decomposes to reactive oxygen species. The reaction in question, which takes place in an aqueous solution, is as such not limited to the mitochondrial membrane where scavenging enzymes such as catalase and superoxide dismutase are located. With the experimental rate constant of $0.147 \mathrm{~s}^{-1}$, the dopamine autoxidation reaction is comparably as fast as the monoamine oxidase $B$ catalyzed dopamine decomposition with a rate constant of $1 \mathrm{~s}^{-1}$. By using quantum chemical calculations, we demonstrated that the rate-limiting step is the formation of a hydroxide ion from a water molecule, which attacks the amino group that enters intramolecular Michael addition, giving rise to a pharmacologically inert aminochrome. We have shown that for dopamine stability on a time scale of days, it is essential that the $\mathrm{pH}$ value of the synaptic vesicle interior is acidic. The pathophysiologic correlates of the results are discussed in the context of Parkinson's disease as well as the pathology caused by long-term amphetamine and cocaine administration.

Keywords: dopamine, aminochrome, neurodegeneration, pH, Parkinson disease, reactive oxygen species, oxidative stress

\section{INTRODUCTION}

Dopaminergic neurons, that project to many central nervous system (CNS) areas, have been implicated in a myriad of neurologic diseases including Parkinson's disease, dementia with Lewy bodies and Alzheimer's disease, which are all caused by neurodegeneration (Piggott et al., 1999; Martorana and Koch, 2014). Understanding the molecular basis of neurodegenerative mechanisms is a complex and rapidly developing focus of research in neuropathology. It is currently believed that the major mechanism of neurodegeneration is the formation of the amyloid plaque which causes progressive loss of neural function and ultimately neuron death (Ross and Poirier, 2004; Chiti and Dobson, 2017). An alternative mechanism meanwhile, is the chemical damage of cellular membranes and proteins by reactive radical species, which causes leakage of the membrane and dysfunction of proteins, with subsequent loss of cell function and neuron death. The main sources of reactive oxygen species (ROS) in the CNS are the electron transfer chain, degradation of biogenic amines by monoamine oxidases (MAO), dopamine and noradrenaline autoxidation, and inflammatory processes (Graham, 1978; Pavlin et al., 2016; Herrera et al., 2017). Since the past few years, we have studied MAO-catalyzed decomposition of several monoamines, along with 
irreversible MAO inhibition, with the use of molecular simulations (Borštnar et al., 2011; Vianello et al., 2012; Pavlin et al., 2013; Repič et al., 2014b; Mavri et al., 2016; Poberžnik et al., 2016; Oanca et al., 2017a,c). In the present study, we attempted to further our understanding of monoamine decomposition reactions by addressing the autoxidation mechanism of dopamine degradation, which occurs in an aqueous solution rather than in an enzyme environment.

\section{Experimental Facts: Dopaminergic Synapse}

In catecholaminergic neurons dopamine is synthesized in the cytosol near the synaptic vesicle (Cartier et al., 2010) and readily transported into them by vesicular monoamine transporter 2 (VMAT-2) (Chaudhry et al., 2008). Inside the synaptic vesicle, dopamine stability is aided by its storage in acidic environment, with a $\mathrm{pH}$ of $\sim 5.6$, as against the neutral cytosolic $\mathrm{pH}$ of $\sim 7.1$ and the extracellular $\mathrm{pH}$ of $\sim 7.4$ (Raley-Susman et al., 1991; Schwiening and Boron, 1994; Vincent et al., 1999; Mani and Ryan, 2009). The major pathways of dopaminergic signaling in CNS include classical synaptic signaling (Nikolaus et al., 2007), and extrasynaptic volume transmission, effective in the distance range of a few $\mu \mathrm{m}$, signaling to many neighboring as well as distant synapses and glial cells (Fuxe et al., 2010, 2012; Uchigashima et al., 2016).

\section{Experimental Facts: Spontaneous Dopamine Oxidation}

Dopamine autoxidation occurs in an aqueous solution without enzymes such as MAO, catechol-O-methyltransferases (COMT) or diamine oxidases (DAO). Dopamine first reacts with oxygen, giving rise to the quinone form and superoxide anion, the latter further decomposing to various ROS. The quinone form is capable of intramolecular Michael addition (cyclization), yielding aminochrome, which at physiological conditions represents the rate-determining step. The aminochrome can further polymerize into dark neuromelanin polymer (Baez et al., 1994). Dopamine autoxidation has been the subject of several kinetic studies (Tse et al., 1976; Young and Babbitt, 1983; García-Moreno et al., 1991; Herlinger et al., 1995; Lloyd, 1995; Hermida-Ameijeiras et al., 2004; Salomäki et al., 2018). Garcia-Moreno et al. have shown that cyclisation reaction is very fast at $\mathrm{pH}$ higher than 7.0 , while at $\mathrm{pH}$ lower than 4.5 the dopamine autoxidation intermediates starts to accumulate, suggesting that cyclisation is the ratelimiting step of dopamine autoxidation at acidic pH (GarcíaMoreno et al., 1991). Herlinger et al. measured the kinetics of dopamine autoxidation in the $\mathrm{pH}$ range of $7-9$, inferring a strong $\mathrm{pH}$-dependence and demonstrating that the rate-limiting step does not involve radical species (Herlinger et al., 1995). Lloyd also reported very strong $\mathrm{pH}$-dependent kinetics where the rate constant exponentially depends on $\mathrm{pH}$, and further showed that heavy metal ions such as manganese additionally catalyze the reaction (Lloyd, 1995). Very recently Salomäki et al. have confirmed that at $\mathrm{pH}$ below 5, the intramolecular Michael addition that gives rise to the cyclic aminochrome represents the rate-limiting step (Salomäki et al., 2018).

\section{MATERIALS AND METHODS}

The reaction mechanism of dopamine autoxidation was studied using quantum chemical calculations. Initial structures of dopamine, complexed with various species, were built using the Molden v5.8 software package (Schaftenaar and Noordik, 2000). The initial geometries of the structures were optimized at the M06-2X/6-31+G(d,p) level which is a good compromise between the computational costs and the reliability of results. The effects of solvation were considered by applying the solvent reaction field of Tomasi and coworkers (Miertuš et al., 1981). In the aforementioned solvation model, the solute cavity is composed of interlocking spheres and the solvent is described as a dielectric continuum. To represent the aqueous solution, a dielectric constant of 78.3 which corresponds to the experimental dielectric constant of bulk water, was applied and geometries of all structures were re-optimized by including the solvent reaction field (Schutz and Warshel, 2001). By inclusion of solvent reaction field, the Born-Oppenheimer surface obtains meaning of free energy surface and from stationary points one can draw conclusions about thermodynamics and kinetics. The same procedure was applied for the products' minima. Transition state search started from the manually-set initial geometry. For all stationary points, a vibrational analysis was performed in the harmonic approximation. Calculated frequencies allowed for zero-point correction of reaction and activation free energies. Reactants' and product' minima were proven to be real minima by having all real frequencies, while the transition states should have one imaginary frequency and the corresponding eigenvector of the latter should describe the reactive motion. Calculations were performed with the Gaussian 09 software package (Frisch et al., 2016). Such quantum chemical methods with proper inclusion of solvent effects, represent an established tool for studying binding and reactivity (Pisliakov et al., 2009; Eizaguirre et al., 2011; Rosta and Warshel, 2012; Sharir-Ivry et al., 2015; Khan et al., 2018).

Free energy differences, associated with proton transfer from the ionizable group with a certain $\mathrm{pK}_{\mathrm{a}}$ value to bulk water with a certain $\mathrm{pH}$ value, were calculated using the following equation (Equation 1)

$$
\Delta G^{\neq}=k_{B} T \ln (10)(p K a-p H)
$$

We considered a few possible reaction mechanisms and the results are described below.

\section{RESULTS}

\section{Dopamine O-Quinone Does not React With Two Water Molecules}

The reactants complex consisted of a dopamine o-quinone molecule and two water molecules. Two water molecules were placed so that they would act as proton acceptors, one in the hydrogen bond with the amino group $\left(-\mathrm{NH}_{2}\right)$, and the other in the weak hydrogen bond involving the scissile $\mathrm{C}-\mathrm{H}$ hydrogen atom. To prevent rupture of the hydrogen bonds in the geometry optimization process, both $\mathrm{C}-\mathrm{O}$ and $\mathrm{N}-\mathrm{O}$ distances 


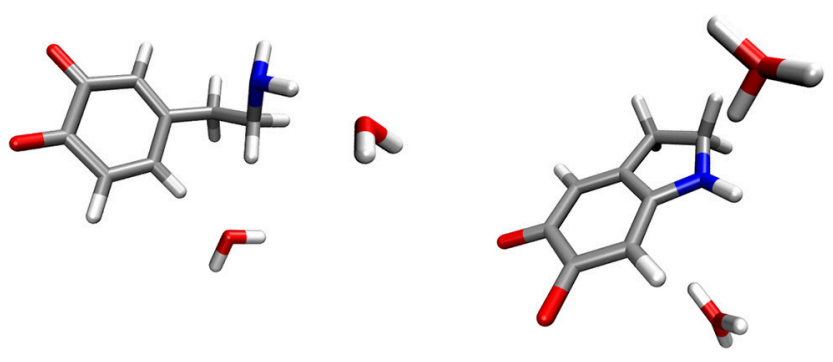

FIGURE 1 | Optimized geometries (energy minima) of the reactants (left) and products (right) complexes. Reactants consist of a complex between dopamine o-quinone and two water molecules. Products consist of cyclized double charged dopamine o-quinone and two hydronium ions $\left(\mathrm{H}_{3} \mathrm{O}^{+}\right)$.

Carbon atoms are colored gray, oxygen atoms red, hydrogen atoms white and nitrogen atoms blue.

were constrained to $3 \AA$ for the reactants complex. For the products complex, consisting of one aminochrome molecule and two hydronium ions, all six $\mathrm{O}-\mathrm{H}$ distances in both hydronium ions were constrained to $0.963 \AA$, as suggested by Kollman et al. (Kollman and Bender, 1973). All other degrees of freedom were fully optimized. The resulting optimized geometries for the reactants and products complexes are shown in Figure 1. A comparison of energies corresponding to the energy minima reveals that the reaction is strongly endergonic with the reaction free energy of $148.51 \mathrm{kcal} \mathrm{mol}^{-1}$, clearly proving that the reaction does not proceed via this mechanism. Therefore, we did not advance with transition state search and zero-point correction for this mechanism.

\section{Dopamine O-Quinone Probably Does Not React Simultaneously With Two Hydroxide Ions}

The reactants complex, consisting of a dopamine o-quinone molecule and two hydroxide ions, was built so that the oxygen atoms of both hydroxide ions were acting as proton acceptors, one in the hydrogen bond with the amino group $\left(-\mathrm{NH}_{2}\right)$, and the other in the weak hydrogen bond involving scissile $\mathrm{C}-\mathrm{H}$ hydrogen atom. The products complex involved one aminochrome molecule and two water molecules. A comparison of energies between the minima shows the reaction is strongly exergonic with the reaction free energy of $-62.70 \mathrm{kcal} \mathrm{mol}^{-1}$. However, this reaction mechanism is not plausible since the formation of two hydroxide ions at $\mathrm{pH}=7.4$ requires $2 \times$ $k_{B} T \ln (10)(15.7-7.4)=22.6 \mathrm{kcal} \mathrm{mol}^{-1}$ in terms of free energy, taking into account the experimental $\mathrm{pK}_{\mathrm{a}}=15.7$ value for water molecule (Bronsted, 1928). Please note that the intrinsic barrier for the reaction with two hydroxide ions plus free energy of deprotonation of the dopamine o-quinone amino group should be added to this value. Dopamine o-quinone has a $\mathrm{pK}_{\mathrm{a}}$ value of 9.58 (Young and Babbitt, 1983), therefore protonated amino group $\left(-\mathrm{NH}_{3}^{+}\right)$deprotonation cost in terms of free energy equals to $k_{B} T \ln (10)(9.58-7.4)=2.96 \mathrm{kcal} \mathrm{mol}^{-1}$. The numerical procedure to locate the transition state and calculate the activation-free energy failed. From this it can be concluded

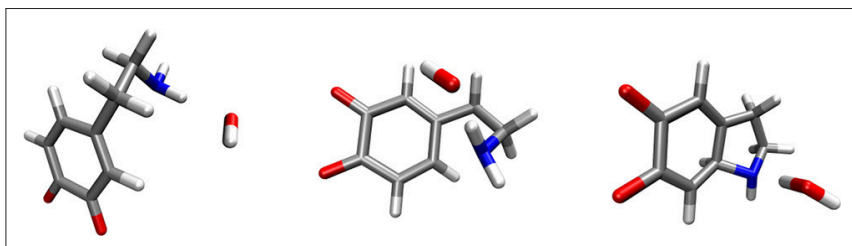

FIGURE 2 | Optimized geometries (energy minima) of the reactants (left), transition state (middle) and products (right) complexes. Reactants consist of a complex between dopamine o-quinone and a hydroxide ion $\left(\mathrm{OH}^{-}\right)$. Products consist of cyclized single charged dopamine o-quinone and a water molecule. Carbon atoms are colored gray, oxygen atoms red, hydrogen atoms white and nitrogen atoms blue.

that the mechanism utilizing a simultaneous attack by two hydroxide ions is probably not plausible, due to a too high activation-free energy.

\section{Dopamine O-Quinone Reacts With One Hydroxide Ion}

A hydroxide ion can form a hydrogen bond with, and abstracts a proton from either the amino group or the scissile $\mathrm{C}-\mathrm{H}$ group. Both possibilities were considered. In the scenario where the hydroxide ion attacked the $\mathrm{C}-\mathrm{H}$ group, the reaction free energy was $9.67 \mathrm{kcal} \mathrm{mol}^{-1}$, suggesting that this is not the preferred reaction channel. Moreover, cyclization did not occur. In the scenario where the hydroxide ion attacked the neutral amino group, the reaction-free energy was $-27.79 \mathrm{kcal} \mathrm{mol}^{-1}$. The corresponding activation free energy was $6.78 \mathrm{kcal} \mathrm{mol}^{-1}$. The optimized geometries of the reactants, transition state and products complexes for this reaction step are shown in Figure 2.

In order to calculate the complete activation free energy for this rate-limiting step, which would be comparable to the experimental value, it is necessary to add the following to the intrinsic activation-free energy: the free energy of hydroxide ion formation $k_{B} T \ln (10)(15.7-7.4)=11.3 \mathrm{kcal} \mathrm{mol}^{-1}$, and the free energy of deprotonation of the dopamine o-quinone amino group $k_{B} T \ln (10)(9.58-7.4)=2.96 \mathrm{kcal} \mathrm{mol}^{-1}$. Please note that the protonated amino group $\left(-\mathrm{NH}_{3}^{+}\right)$does not enter the intramolecular Michael addition, as is also the case for MAO catalyzed decomposition of biogenic amines (Oanca et al., 2017b). As such, the calculated activation-free energy for this rate-limiting step equals $21.0 \mathrm{kcal} \mathrm{mol}^{-1}$. After the above-noted step, another step follows-abstraction of the $\mathrm{C}-\mathrm{H}$ proton by an additional hydroxide ion. For this latter step, the transition state was located with the classical barrier of $1.54 \mathrm{kcal} \mathrm{mol}^{-1}$. After vibrational energy correction for both the reactants and the transition state, this reaction step proved to be barrier-less. Formation of the hydroxide ion $\left(11.3 \mathrm{kcal} \mathrm{mol}^{-1}\right)$ is therefore the only constituent of the energy barrier for this second step, and consequently does not control the overall reaction rate. The rate-limiting reaction mechanism is depicted in Figure 3.

\section{Dopamine O-Quinone Autoxidation Is Strongly pH-Dependent}

Suggested mechanism of dopamine reaction with one hydroxide ion allows us to analytically express the activation-free energy as 


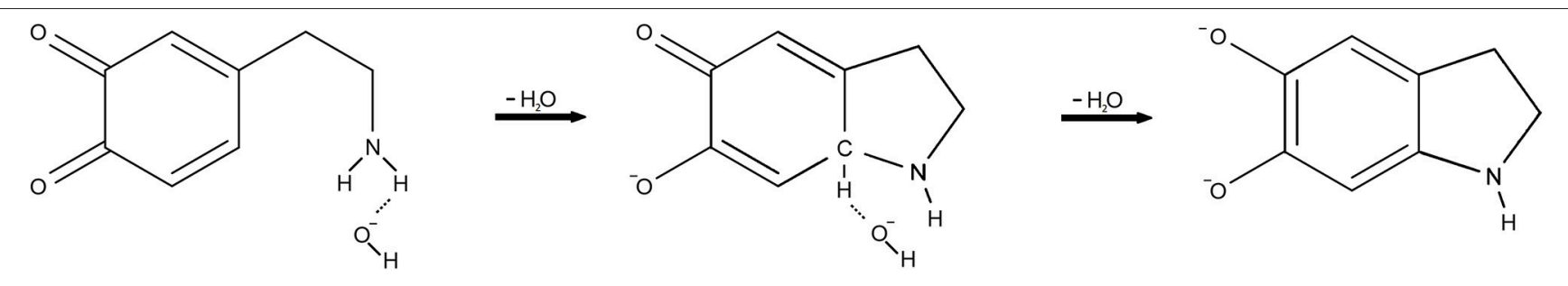

FIGURE 3 | The reaction mechanism of dopamine autoxidation. Our calculations give evidence that at physiologic pH the rate-limiting step is the formation of a hydroxide ion $\left(\mathrm{OH}^{-}\right)$from a water molecule, which then attacks the amino group $\left(-\mathrm{NH}_{2}\right)$ of dopamine o-quinone This is preceded by amino group deprotonation, since protonated amino group $\left(-\mathrm{NH}_{3}^{+}\right)$does not enter the intramolecular Michael addition. After the above-noted step, abstraction of the $\mathrm{C}-\mathrm{H}$ proton by an additional hydroxide ion $\left(\mathrm{OH}^{-}\right)$follows.

a function of the $\mathrm{pH}$ value of the solution using the following equation (Equation 2):

$$
\begin{aligned}
\Delta G^{\neq} & =6.78 \mathrm{kcal} \mathrm{mol}^{-1}+k_{B} T \ln (10)(15.7-p H) \\
& +k_{B} T \ln (10)(9.58-p H)
\end{aligned}
$$

Note that at acidic $\mathrm{pH}$, the free energy cost for hydroxide ion and neutral amino group formation is much higher than at neutral $\mathrm{pH}$. Inserting this expression into the transition state equation which links activation energy $\Delta \mathrm{G}^{\neq}$with the reaction rate constant $\mathrm{k}_{\text {rate }}$.

$$
k_{\text {rate }}=\frac{k_{B} T}{h} e^{-\left(\frac{\Delta G^{\neq}}{k_{B} T}\right)}
$$

yields the $\mathrm{pH}$-dependence:

$k_{\text {rate }}(p H)=\frac{k_{B} T}{h} e^{-\left(\frac{6.78 \mathrm{kcal} \mathrm{mol}^{-1}+k_{B} T \ln (10)(15.7-p H)+k_{B} T \ln (10)(9.58-p H)}{k_{B} T}\right)}$

from which we can derive the following (Equation 5):

$$
k_{\text {rate }}(p H)=10^{-(c-2 p H)}
$$

The above derived functional equation yields results that are fully consistent with the dependence of the dopamine autoxidation rate constant upon $\mathrm{pH}$-described by Lloyd (1995).

In Table 1, a few rate constant values are provided, calculated using Equation 4. The corresponding $\mathrm{pH}$-dependence of the rate constant is graphically shown in Figure 4. Note that the function is shifted horizontally relative to the experimental $k_{\text {rate }}$ described by Tse et al. and Lloyd, who performed the experiments in the presence of magnesium ions that might change the kinetic data to certain extent, while the shape is practically identical to the function shown by Lloyd (Tse et al., 1976; Lloyd, 1995).

\section{DISCUSSION}

The results of the presented quantum chemical calculations show that the rate-limiting step of dopamine autoxidation is controlled by a sum of three free energy values: (1) formation of a hydroxide ion in water; (2) dopamine o-quinone charged
TABLE 1 | A few rate constants and the corresponding reaction half-times for dopamine autoxidation in an aqueous solution as a function of the $\mathrm{pH}$ value, calculated using Equation 4.

\begin{tabular}{lcc}
\hline $\mathbf{p H}$ & $\mathbf{k}_{\text {rate }}\left(\mathbf{s}^{-\mathbf{1}}\right)$ & $\mathbf{t}_{1 / 2}$ \\
\hline 5.6 & 0.000000591 & 13.5 days \\
7.1 & 0.000586 & $19.7 \mathrm{~min}$ \\
7.4 & 0.00233 & $4.95 \mathrm{~min}$ \\
8.0 & 0.0368 & $18.8 \mathrm{~s}$ \\
9.58 & 52.8 & $0.0131 \mathrm{~s}$ \\
\hline
\end{tabular}

amino group $\left(-\mathrm{NH}_{3}^{+}\right)$deprotonation; and (3) the intrinsic barrier for the reaction. The latter value is $\mathrm{pH}$-independent, while the entire process is strongly $\mathrm{pH}$-dependent. At a $\mathrm{pH}$ lower than 5.6, dopamine has a half-life on a time scale of days, while at a $\mathrm{pH}$ of 7.4, the entirety of dopamine reserves would disappear in only a few minutes. This emphasizes the role of the acidic interior of synaptic vesicles in dopamine stability and metabolism.

Autoxidation of dopamine has been investigated since the past few decades (Young and Babbitt, 1983; Herlinger et al., 1995; Lloyd, 1995; Hermida-Ameijeiras et al., 2004; Salomäki et al., 2018). Dopamine o-quinone cyclization at physiological $\mathrm{pH}$ values is very fast, with a rate constant of $0.147 \mathrm{~s}^{-1}$ and a halflife of $4.7 \mathrm{~s}$, making the reaction mechanism almost impossible to investigate experimentally (Tse et al., 1976). To overcome this limitation, we used quantum chemical computation methods to elucidate the exact reaction mechanism, further utilizing it to explain the mechanism of strong $\mathrm{pH}$-dependence. We found that at physiological $\mathrm{pH}$, the rate-limiting step is the formation of a hydroxide ion. Our analytical expression for the $\mathrm{pH}$ dependence of the rate constant (Equation 4) is fully consistent with the experimental pH-dependence shown by Lloyd (1995) and Salomäki et al. (2018), affirming the validity of our results.

The calculated activation-free energy for the cyclization reaction equals $21.0 \mathrm{kcal} \mathrm{mol}^{-1}$. This is reasonably close to the experimental barrier of $18.5 \mathrm{kcal} \mathrm{mol}^{-1}$ (Tse et al., 1976) at $\mathrm{pH}$ value of 7.4, considered that experimental determination of $\mathrm{pK}_{\mathrm{a}}$ values of reaction intermediates and ionizable protein groups is not easy (Mildvan et al., 2002; Bezençon et al., 2014). Calculations concerning $\mathrm{pK}_{\mathrm{a}}$ values are extremely demanding, typically involve errors of at least one $\mathrm{pK}_{\mathrm{a}}$ unit, and thus represent a very 


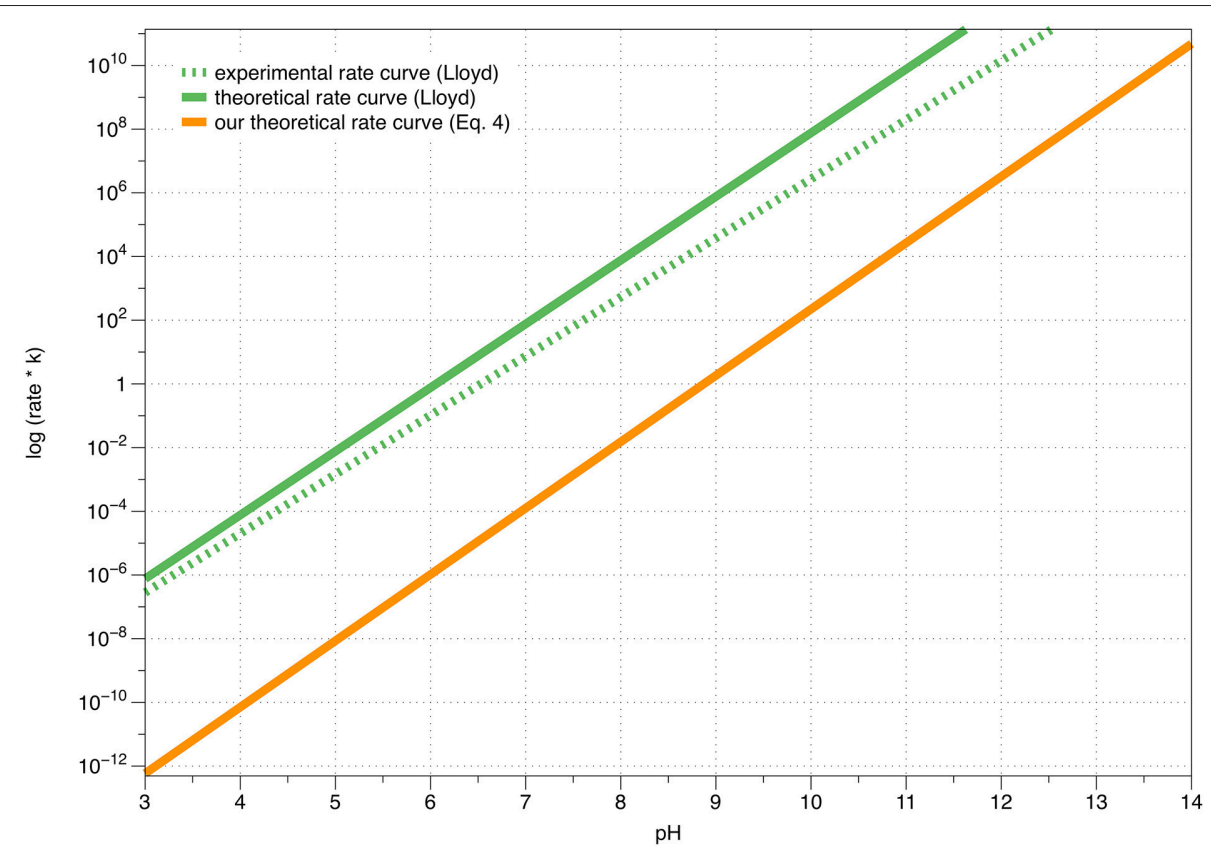

FIGURE 4 | A graphical comparison between Lloyd's experimental, Lloyd's theoretical and our own calculated theoretical (Equation 4) rate constants of dopamine autoxidation in aqueous solution, as a function of the $\mathrm{pH}$ value.

strict test of the applied computational methodology (Warshel, 1981; Warshel et al., 2006; Borštnar et al., 2012; Repič et al., 2014a). An important source of error is also the calculation of hydration-free energy of the hydroxide ion that enters the reaction, as its negative charge gradually redistributes over the entire reactive complex throughout the course of the reaction. For ionic species, the hydration-free energy error calculated using a solvent reaction field is about $3 \mathrm{kcal} \mathrm{mol}^{-1}$ (Kelly et al., 2006). This accounts for the discrepancy between the experimentallyderived and calculated activation-free energy and rate constants.

$\mathrm{Gu}$ et al. demonstrated that in dopaminergic neurons, dopamine is released by a transient reversible fusion mechanism known as "kiss and run" (Gu et al., 2015). These characteristics could be understood as neuron adaptations for handling with neurotoxic dopamine by ensuring faster synaptic vesicle reacidification. Another strategy could be a physical and functional coupling of the enzymes for dopamine synthesis and VMAT-2, which immediately after synthesis transports and stores dopamine into acidic synaptic vesicles (Cartier et al., 2010). A third plausible mechanism to combat dopamine toxicity could be the physical and functional coupling of dopamine transporter (DAT) and VMAT-2 by scaffold proteins (Egaña et al., 2009), resulting in re-uptaken dopamine being immediately transported into the acidic vesicle interior.

In the case of classic synaptic transmission from presynaptic to the postsynaptic neuron, the synaptic gap is only $20-30 \mathrm{~nm}$ wide, which makes it very sensitive to $\mathrm{pH}$ change resulting from the release of protons from synaptic vesicles and the transient incorporation of vesicular $\mathrm{H}^{+}$-ATPase into the presynaptic membrane (Sinning and Hübner, 2013). Such brief but strong acidification of the synaptic gap and the resulting stabilization of dopamine could be essential for the classical synaptic dopamine transmission in the corpus striatum, where dopamine uptake by DAT is the most important determinant of dopamine signaling (Rice and Cragg, 2008). In the midbrain however, where volume transmission at a distance scale of $\mu \mathrm{m}$ takes place, dopamine rapidly diffuses to extrasynaptic regions where the $\mathrm{pH}$ is above 7 (Cragg et al., 2001). In such setting, the major factors influencing the time course of dopamine signaling are the diffusion rate and the $\mathrm{pH}$-dependent rate of dopamine autoxidation.

Parkinson's disease is a neurodegenerative disease localized to the nigrostriatal pathway, where the major pathophysiological process is a degeneration of dopaminergic neurons. Despite intensive research into Parkinson's disease pathophysiology, the initial trigger of neuron degeneration is still unknown. It is generally accepted that $\alpha$-synuclein aggregation, mitochondrial dysfunction, neuroinflammation, dysfunction of protein degradation and oxidative stress are involved in neurodegeneration. In the last decades, it has been shown that aminochrome, the product of dopamine autoxidation, can induce most of these changes and that the rate of some of them is $\mathrm{pH}$ dependent (García-Moreno et al., 1991; Paris et al., 2010; SeguraAguilar et al., 2014; Herrera et al., 2017; Segura-Aguilar and Huenchuguala, 2018), suggesting that dopamine autoxidation could be one of the major pathophysiologic processes, and possibly even the major cause of Parkinson's disease. Mosharov et al. showed that elevated cytosolic concentrations of dopamine and its metabolites are cytotoxic, and noted that dopaminergic neurons in substantia nigra are especially susceptible to dopamine neurotoxicity compared to the more resistant 
dopaminergic neurons in the ventral tegmental area. They partially attributed this effect to higher cytosolic dopamine concentrations in neurons of substantia nigra (Mosharov et al., 2009), which can potentially explain the localized nature of Parkinson's disease.

The rate of dopamine autoxidation outside the synaptic vesicles is probably comparable to a MAO-B-catalyzed reaction (Pavlin et al., 2016). An indirect indication supporting this assumption is the fact that only a slight increase of extracellular dopamine concentration and subsequent excitation of postsynaptic dopamine receptors can be seen following an irreversible inhibition of MAO A or MAO B by phenelzine, selegiline or rasagiline (McKim et al., 1983; Kaseda et al., 1999; Albreht et al., 2018). This could explain the relatively modest effect of selegiline and rasagiline monotherapy in the treatment of Parkinson's disease (Dezsi and Vecsei, 2017), and also raises a concern regarding MAO B inhibition, which would as such increase dopamine autoxidation and subsequent aminochrome formation. Note that MAO B is located at the outer mitochondrial membrane, where are ROS scavenging enzymes are also colocated (Goldstein et al., 2017).

The amount of autoxidized dopamine and therewith associated ROS production is proportional to the level of cytosolic dopamine. Inhibition of DAT and VMAT-2 by amphetamines, leads to increased levels of dopamine in the synaptic gap, cytoplasm and extracellular space (Ciccarone, 2011). All three compartments have a $\mathrm{pH}$ of about 7 , giving rise to rapid dopamine autoxidation. This could explain the increased susceptibility to development of Parkinson's disease in long-term amphetamine users (Lloyd et al., 2006; Curtin et al., 2015). Cytosolic dopamine levels are also dependent on the level of dopamine precursors and the activity of the catalytic enzymes that include phenylalanine hydroxylase $(\mathrm{PAH})$ that is cofactor tetrahydrobiopterin (BH4) dependent. Thus, chronic CNS inflammation pathologies where IFN $\gamma$ induces $\mathrm{BH} 4$ synthesis might lead to increased dopamine levels and increased incidence of neurodegeneration (Murr et al., 2014).

Since $\mathrm{pH}$ is physiologically very strictly regulated, its manipulation probably cannot be used to modulate dopamine autoxidation rate in vivo. Moreover, Pham et al. showed that the formation of insoluble $\alpha$-synuclein oligomers is increased at acidic $\mathrm{pH}$ (Pham et al., 2009). It has also been suggested that at slightly acidic $\mathrm{pH}$ a toxic $6 \mathrm{OH}$-dopamine could be formed during dopamine autoxidation (García-Moreno et al., 1991). Therefore, we believe that the best strategy to ameliorate dopamine autoxidation toxicity is to reduce or eliminate its toxic by-products such as ROS and aminochrome by modulation of activity of various antioxidants and the enzymes including

\section{REFERENCES}

Albreht, A., Vovk, I., Mavri, J., Marco-Contelles, J., and Ramsay, R. R. (2018). Evidence for a cyanine link between propargylamine drugs and monoamine oxidase clarifies the inactivation mechanism. Front. Chem. 6:169. doi: 10.3389/fchem.2018.00169

Baez, S., Linderson, Y., and Segura-Aguilar, J. (1994). Superoxide dismutase and catalase prevent the formation of reactive oxygen species during reduction
glutathione-S-transferase M2 (GSTM2) and DT-diaphorase (Pavlin et al., 2016; Herrera et al., 2017).

Our study has a few limitations. First, the applied computational methods were limited to the quantum-chemical description of the reactive species, while solvent effects were included on the level of solvent reaction field. Explicit description of solvent, counterions and thermal fluctuations on the level of multiscale simulation is computationally demanding and would not significantly change the results (Warshel and Levitt, 1976). Second, we studied autoxidation of dopamine in aqueous solution, while the influence of other molecules or ions were not investigated. Third, the current study is limited to dopamine autoxidation and does not include pathways of dopamine synthesis and enzymatic decomposition. The latter is catalyzed by MAO B and represents additional source of reactive oxygen species (Pavlin et al., 2016).

\section{CONCLUSION}

We have studied the reaction mechanism of dopamine autoxidation using quantum chemical methods, and shown that at the physiologic $\mathrm{pH}$ the rate-limiting step is the formation of a hydroxide ion. An analytical solution for describing the $\mathrm{pH}$-dependence of the rate constant is derived. The proposed model is fully consistent with experimental data. A strongly $\mathrm{pH}$-dependent rate constant supports the assumption that the rate-limiting step involves a heterolytic reaction and that a reaction mechanism involving free radicals is not plausible at physiological conditions. Therefore, for stability of dopamine stored in synaptic vesicles, an acidic interior is essential, since at neutral $\mathrm{pH}$, dopamine would quickly almost completely disappear. We believe that dopamine autoxidation is one of the most important mechanisms in pathophysiology of Parkinson's disease, and the major factor for its localized nature on the nigrostriatal pathway.

\section{AUTHOR CONTRIBUTIONS}

NU, JM, and BG performed the calculations; NU, JM, $\mathrm{BG}, \mathrm{NV}$, and $\mathrm{MS}$ collected the literature and wrote the manuscript.

\section{ACKNOWLEDGMENTS}

JM would like to thank the Slovenian Research Agency for financial support within the framework of the Program Group P1-0012. We would like to thank Ms. Urša Poljanec for proofreading the manuscript.

of cyclized dopa ortho-quinone by DT-diaphorase. Chem. Biol. Interact. 93, 103-116. doi: 10.1016/0009-2797(94)90090-6

Bezençon, J., Wittwer, M. B., Cutting, B., Smieško, M., Wagner, B., Kansy, M., et al. (2014). $\mathrm{p} K_{a}$ determination by ${ }^{1} \mathrm{H}$ NMR spectroscopy-an old methodology revisited. J. Pharm. Biomed. Anal. 93, 147-155. doi: 10.1016/j.jpba.2013. 12.014

Borštnar, R., Repič, M., Kamerlin, S. C., Vianello, R., and Mavri, J. (2012). Computational study of the $\mathrm{p} K_{a}$ values of potential catalytic residues in the 
active site of monoamine oxidase B. J. Chem. Theory Comput. 8, 3864-3870. doi: $10.1021 / \mathrm{ct} 300119 \mathrm{u}$

Borštnar, R., Repič, M., Kržan, M., Mavri, J., and Vianello, R. (2011). Irreversible inhibition of monoamine oxidase $\mathrm{b}$ by the antiparkinsonian medicines rasagiline and selegiline: a computational study. Europ. J. Org. Chem. 2011, 6419-6433. doi: 10.1002/ejoc.201100873

Bronsted, J. N. (1928). Acid and basic catalysis. Chem. Rev. 5, 231-338. doi: $10.1021 / \mathrm{cr} 60019 \mathrm{a} 001$

Cartier, E. A., Parra, L. A., Baust, T. B., Quiroz, M., Salazar, G., Faundez, V., et al. (2010). A biochemical and functional protein complex involving dopamine synthesis and transport into synaptic vesicles. J. Biol. Chem. 285, 1957-1966. doi: 10.1074/jbc.M109.054510

Chaudhry, F. A., Edwards, R. H., and Fonnum, F. (2008). Vesicular neurotransmitter transporters as targets for endogenous and exogenous toxic substances. Annu. Rev. Pharmacol. Toxicol. 48, 277-301. doi: 10.1146/annurev.pharmtox.46.120604.141146

Chiti, F., and Dobson, C. M. (2017). Protein misfolding, amyloid formation, and human disease: a summary of progress over the last decade. Annu. Rev. Biochem. 86, 27-68. doi: 10.1146/annurev-biochem-061516-045115

Ciccarone, D. (2011). Stimulant abuse: pharmacology, cocaine, methamphetamine, treatment, attempts at pharmacotherapy. Prim. Care 38, 41-58. doi: 10.1016/j.pop.2010.11.004

Cragg, S. J., Nicholson, C., Kume-Kick, J., Tao, L., and Rice, M. E. (2001). Dopamine-mediated volume transmission in midbrain is regulated by distinct extracellular geometry and uptake. J. Neurophysiol. 85, 1761-1771. doi: $10.1152 /$ jn.2001.85.4.1761

Curtin, K., Fleckenstein, A. E., Robison, R. J., Crookston, M. J., Smith, K. R., and Hanson, G. R. (2015). Methamphetamine/amphetamine abuse and risk of Parkinson's disease in Utah: a population-based assessment. Drug Alcohol Depend. 146, 30-38.

Dezsi, L., and Vecsei, L. (2017). Monoamine oxidase B inhibitors in Parkinson's Disease. CNS Neurol. Disord. Drug Targets 16, 425-439. doi: $10.2174 / 1871527316666170124165222$

Egaña, L. A., Cuevas, R. A., Baust, T. B., Parra, L. A., Leak, R. K., Hochendoner, S., et al. (2009). Physical and functional interaction between the dopamine transporter and the synaptic vesicle protein synaptogyrin-3. J. Neurosci. 29, 4592-4604. doi: 10.1523/JNEUROSCI.4559-08.2009

Eizaguirre, A., Lamsabhi, A. M., Mó, O., and Yáñez, M. (2011). Assisted intramolecular proton transfer in (uracil) $2 \mathrm{Ca} 2+$ complexes. Theor. Chem. Acc. 128, 457-464. doi: 10.1007/s00214-010-0801-Z

Frisch, M. J., Trucks, G. W., Schlegel, H. B., Scuseria, G. E., Robb, M. A., Cheeseman, J. R., et al. (2016). Gaussian 09, Revision A.02. Wallingford, CT: Gaussian Inc.

Fuxe, K., Borroto-Escuela, D. O., Romero-Fernandez, W., Diaz-Cabiale, Z., Rivera, A., Ferraro, L., et al. (2012). Extrasynaptic neurotransmission in the modulation of brain function. Focus on the striatal neuronal-glial networks. Front. Physiol. 3:136. doi: 10.3389/fphys.2012.00136

Fuxe, K., Dahlström, A. B., Jonsson, G., Marcellino, D., Guescini, M., Dam, M., et al. (2010). The discovery of central monoamine neurons gave volume transmission to the wired brain. Prog. Neurobiol. 90, 82-100. doi: 10.1016/j.pneurobio.2009.10.012

García-Moreno, M., Rodríguez-López, J.N., Martínez-Ortiz, F., Tudela, J., Varón, R., and García-Cánovas, F. (1991). Effect of $\mathrm{pH}$ on the oxidation pathway of dopamine catalyzed by tyrosinase. Arch. Biochem. Biophys. 288, 427-434. doi: 10.1016/0003-9861(91)90216-6

Goldstein, D. S., Jinsmaa, Y., Sullivan, P., and Sharabi, Y. (2017). Nacetylcysteine prevents the increase in spontaneous oxidation of dopamine during monoamine oxidase inhibition in PC12 cells. Neurochem. Res. 42, 3289-3295. doi: 10.1007/s11064-017-2371-0

Graham, D. G. (1978). Oxidative pathways for catecholamines in the genesis of neuromelanin and cytotoxic quinones. Mol. Pharmacol. 14, 633-643.

Gu, H., Lazarenko, R. M., Koktysh, D., Iacovitti, L., and Zhang, Q. (2015). A stem cell-derived platform for studying single synaptic vesicles in dopaminergic synapses. Stem Cells Transl. Med. 4, 887-893. doi: 10.5966/sctm.2015-0005

Herlinger, E., Jameson, R. F., and Linert, W. (1995). Spontaneous autoxidation of dopamine. J. Chem. Soc. Perkin Trans. 2:259. doi: 10.1039/p29950000259

Hermida-Ameijeiras, A., Méndez-Alvarez, E., Sánchez-Iglesias, S., SanmartínSuárez, C., and Soto-Otero, R. (2004). Autoxidation and MAO-mediated metabolism of dopamine as a potential cause of oxidative stress: role of ferrous and ferric ions. Neurochem. Int. 45, 103-116. doi: 10.1016/j.neuint.2003.11.018

Herrera, A., Muñoz, P., Steinbusch, H. W. M., and Segura-Aguilar, J. (2017). Are dopamine oxidation metabolites involved in the loss of dopaminergic neurons in the nigrostriatal system in Parkinson's Disease? ACS Chem. Neurosci. 8, 702-711. doi: 10.1021/acschemneuro.7b00034

Kaseda, S., Nomoto, M., and Iwata, S. (1999). Effect of selegiline on dopamine concentration in the striatum of a primate. Brain Res. 815, 44-50. doi: 10.1016/S0006-8993(98)01089-0

Kelly, C. P., Cramer, C. J., and Truhlar, D. G. (2006). Aqueous solvation free energies of ions and ion-water clusters based on an accurate value for the absolute aqueous solvation free energy of the proton. J. Phys. Chem. B 110, 16066-16081. doi: 10.1021/jp063552y

Khan, Y. S., Gutiérrez-De-Terán, H., and Åqvist, J. (2018). Molecular mechanisms in the selectivity of nonsteroidal anti-inflammatory drugs. Biochemistry 57, 1236-1248. doi: 10.1021/acs.biochem.7b01019

Kollman, P. A., and Bender, C. F. (1973). The structure of the H3O+ (hydronium) ion. Chem. Phys. Lett. 21, 271-274. doi: 10.1016/0009-2614(73)80133-2

Lloyd, R. V. (1995). Mechanism of the manganese-catalyzed autoxidation of dopamine. Chem. Res. Toxicol. 8, 111-116. doi: 10.1021/tx00043a015

Lloyd, S. A., Faherty, C. J., and Smeyne, R. J. (2006). Adult and in utero exposure to cocaine alters sensitivity to the Parkinsonian toxin 1-methyl-4-phenyl-1,2,3,6-tetrahydropyridine. Neuroscience 137, 905-913. doi: 10.1016/j.neuroscience.2005.09.035

Mani, M., and Ryan, T. A. (2009). Live imaging of synaptic vesicle release and retrieval in dopaminergic neurons. Front. Neural Circuits 3:3. doi: 10.3389/neuro.04.003.2009

Martorana, A., and Koch, G. (2014). Is dopamine involved in Alzheimer's disease? Front. Aging Neurosci. 6:252. doi: 10.3389/fnagi.2014.00252

Mavri, J., Matute, R. A., Chu, Z. T., and Vianello, R. (2016). Path integral simulation of the H/D kinetic isotope effect in monoamine oxidase B catalyzed decomposition of dopamine. J. Phys. Chem. B 120, 3488-3492. doi: 10.1021/acs.jpcb.6b00894

McKim, R. H., Calverly, D. G., Dewhurst, W. G., and Baker, G. B. (1983). Regional concentrations of cerebral amines: effects of tranylcypromine and phenelzine. Prog. Neuropsychopharmacol. Biol. Psychiatry 7, 783-786. doi: 10.1016/0278-5846(83)90066-0

Miertuš, S., Scrocco, E., and Tomasi, J. (1981). Electrostatic interaction of a solute with a continuum. A direct utilizaion of ab initio molecular potentials for the prevision of solvent effects. Chem. Phys. 55, 117-129. doi: 10.1016/0301-0104(81)85090-2

Mildvan, A. S., Massiah, M. A., Harris, T. K., Marks, G. T., Harrison, D. H. T., Viragh, C., et al. (2002). Short, strong hydrogen bonds on enzymes: NMR and mechanistic studies. J. Mol. Struct. 615, 163-175. doi: 10.1016/S0022-2860(02)00212-0

Mosharov, E. V., Larsen, K. E., Kanter, E., Phillips, K. A., Wilson, K., Schmitz, Y., et al. (2009). Interplay between cytosolic dopamine, calcium, and $\alpha$-synuclein causes selective death of substantia nigra neurons. Neuron 62, 218-229. doi: 10.1016/j.neuron.2009.01.033

Murr, C., Grammer, T. B., Meinitzer, A., Kleber, M. E., März, W., and Fuchs, D. (2014). Immune activation and inflammation in patients with cardiovascular disease are associated with higher phenylalanine to tyrosine ratios: the ludwigshafen risk and cardiovascular health study. J. Amino Acids 2014:783730. doi: 10.1155/2014/783730

Nikolaus, S., Antke, C., Kley, K., Poeppel, T. D., Hautzel, H., Schmidt, D., et al. (2007). Investigating the dopaminergic synapse in vivo. I. molecular imaging studies in humans. Rev. Neurosci. 18, 439-472. doi: 10.1515/REVNEURO.2007.18.6.439

Oanca, G., Stare, J., and Mavri, J. (2017a). How fast monoamine oxidases decompose adrenaline? Kinetics of isoenzymes A and B evaluated by empirical valence bond simulation. Proteins $85,2170-2178$.

Oanca, G., Stare, J., and Mavri, J. (2017b). How fast monoamine oxidases decompose adrenaline? Kinetics of isoenzymes A and B evaluated by empirical valence bond simulation. Proteins Struct. Funct. Bioinforma. 85, 2170-2178. doi: $10.1002 /$ prot. 25374

Oanca, G., Stare, J., Vianello, R., and Mavri, J. (2017c). Multiscale simulation of monoamine oxidase catalyzed decomposition of phenylethylamine analogs. Eur. J. Pharmacol. 817, 46-50. doi: 10.1016/j.ejphar.2017.05.061 
Paris, I., Perez-Pastene, C., Cardenas, S., Iturriaga-Vasquez, P., Muñoz, P., et al. (2010). Aminochrome induces disruption of actin, alpha-, and beta-tubulin cytoskeleton networks in substantia-nigra-derived cell line. Neurotox. Res. 18, 82-92. doi: 10.1007/s12640-009-9148-4

Pavlin, M., Mavri, J., Repič, M., and Vianello, R. (2013). Quantum-chemical approach to determining the high potency of clorgyline as an irreversible acetylenic monoamine oxidase inhibitor. J. Neural Transm. 120, 875-882. doi: 10.1007/s00702-013-1016-y

Pavlin, M., Repič, M., Vianello, R., and Mavri, J. (2016). The chemistry of neurodegeneration: kinetic data and their implications. Mol. Neurobiol. 53, 3400-3415. doi: 10.1007/s12035-015-9284-1

Pham, C. L. L., Leong, S. L., Ali, F. E., Kenche, V. B., Hill, A. F., Gras, S. L., et al. (2009). Dopamine and the dopamine oxidation product 5,6dihydroxylindole promote distinct on-pathway and off-pathway aggregation of $\alpha$-synuclein in a pH-dependent manner. J. Mol. Biol. 387, 771-785. doi: 10.1016/j.jmb.2009.02.007

Piggott, M. A., Marshall, E. F., Thomas, N., Lloyd, S., Court, J. A., Jaros, E., et al. (1999). Striatal dopaminergic markers in dementia with Lewy bodies, Alzheimer's and Parkinson's diseases: rostrocaudal distribution. Brain 122, 1449-1468.

Pisliakov, A. V., Cao, J., Kamerlin, S. C. L., and Warshel, A. (2009). Enzyme millisecond conformational dynamics do not catalyze the chemical step. Proc. Natl. Acad. Sci. U.S.A. 106, 17359-17364. doi: 10.1073/pnas.0909150106

Poberžnik, M., Purg, M., Repic, M., Mavri, J., and Vianello, R. (2016). Empirical valence bond simulations of the hydride-transfer step in the monoamine oxidase a catalyzed metabolism of noradrenaline. J. Phys. Chem. B 120, 11419-11427. doi: 10.1021/acs.jpcb.6b09011

Raley-Susman, K. M., Cragoe, E. J., Sapolsky, R. M., and Kopito, R. R. (1991). Regulation of intracellular $\mathrm{pH}$ in cultured hippocampal neurons by an amiloride-insensitive $\mathrm{Na}+/ \mathrm{H}+$ exchanger. J. Biol. Chem. 266, 2739-2745.

Repič, M., Purg, M., Vianello, R., and Mavri, J. (2014a). Examining electrostatic preorganization in monoamine oxidases $\mathrm{A}$ and $\mathrm{B}$ by structural comparison and $\mathrm{p} K_{a}$ calculations. J. Phys. Chem. B 118, 4326-4332. doi: 10.1021/jp50 $0795 \mathrm{p}$

Repič, M., Vianello, R., Purg, M., Duarte, F., Bauer, P., Kamerlin, S. C., et al. (2014b). Empirical valence bond simulations of the hydride transfer step in the monoamine oxidase B catalyzed metabolism of dopamine. Proteins Struct. Funct. Bioinforma. 82, 3347-3355. doi: 10.1002/prot. 24690

Rice, M. E., and Cragg, S. J. (2008). Dopamine spillover after quantal release: rethinking dopamine transmission in the nigrostriatal pathway. Brain Res. Rev. 58, 303-313. doi: 10.1016/j.brainresrev.2008.02.004

Ross, C. A., and Poirier, M. A. (2004). Protein aggregation and neurodegenerative disease. Nat. Med. 10, S10-S17. doi: 10.1038/nm1066

Rosta, E., and Warshel, A. (2012). Origin of linear free energy relationships: exploring the nature of the off-diagonal coupling elements in SN2 reactions. J. Chem. Theory Comput. 8, 3574-3585. doi: 10.1021/ct20 09329

Salomäki, M. O., Marttila, L., Kivelä, H., Ouvinen, T., and Lukkari, J. O. (2018). Effect of $\mathrm{pH}$ and oxidant on the first steps of polydopamine formation: a thermodynamic approach. J. Phys. Chem. B 122:8b02304. doi: 10.1021/acs.jpcb.8b02304

Schaftenaar, G., and Noordik, J. H. (2000). Molden: a pre- and post-processing program for molecular and electronic structures. J. Comput. Aided. Mol. Des. 14, 123-134. doi: 10.1023/A:1008193805436
Schutz, C. N., and Warshel, A. (2001). What are the dielectric "constants" of proteins and how to validate electrostatic models? Proteins Struct. Funct. Genet. 44, 400-417. doi: 10.1002/prot.1106

Schwiening, C. J., and Boron, W. F. (1994). Regulation of intracellular $\mathrm{pH}$ in pyramidal neurones from the rat hippocampus by $\mathrm{Na}^{+}$-dependent $\mathrm{Cl}^{-}-\mathrm{HCO}_{3}$ exchange. J. Physiol. 475, 59-67. doi: 10.1113/jphysiol.1994.sp020049

Segura-Aguilar, J., and Huenchuguala, S. (2018). Aminochrome induces irreversible mitochondrial dysfunction by inducing autophagy dysfunction in Parkinson's Disease. Front. Neurosci. 12:106. doi: 10.3389/fnins.2018.00106

Segura-Aguilar, J., Paris, I., Muñoz, P., Ferrari, E., Zecca, L., and Zucca, F. A. (2014). Protective and toxic roles of dopamine in Parkinson's disease. J. Neurochem. 129, 898-915. doi: 10.1111/jnc.12686

Sharir-Ivry, A., Varatharaj, R., and Shurki, A. (2015). Valence bond and enzyme catalysis: a time to break down and a time to build up. Chem. A Eur. J. 21, 7159-7169. doi: 10.1002/chem.201406236

Sinning, A., and Hübner, C. A. (2013). Minireview: pH and synaptic transmission. FEBS Lett. 587, 1923-1928. doi: 10.1016/j.febslet.2013.04.045

Tse, D. C., McCreery, R. L., and Adams, R. N. (1976). Potential oxidative pathways of brain catecholamines. J. Med. Chem. 19, 37-40. doi: 10.1021/jm00223a008

Uchigashima, M., Ohtsuka, T., Kobayashi, K., and Watanabe, M. (2016). Dopamine synapse is a neuroligin-2-mediated contact between dopaminergic presynaptic and GABAergic postsynaptic structures. Proc. Natl. Acad. Sci. U.S.A. 113, 4206-4211. doi: 10.1073/pnas.1514074113

Vianello, R., Repič, M., and Mavri, J. (2012). How are biogenic amines metabolized by monoamine oxidases? Eur. J. Org. Chem. 2012, 7057-7065. doi: 10.1002/ejoc.201201122

Vincent, A. M., TenBroeke, M., and Maiese, K. (1999). Neuronal intracellular pH directly mediates nitric oxide-induced programmed cell death. J. Neurobiol. 40, 171-184. doi: 10.1002/(SICI)1097-4695(199908)40:2\&lt;171::AIDNEU4\&gt;3.0.CO;2-F

Warshel, A. (1981). Calculations of enzymatic reactions: calculations of $\mathrm{pKa}$, proton transfer reactions, and general acid catalysis reactions in enzymes. Biochemistry 20, 3167-3177. doi: 10.1021/bi00514a028

Warshel, A., and Levitt, M. (1976). Theoretical studies of enzymic reactions: dielectric, electrostatic and steric stabilization of the carbonium ion in the reaction of lysozyme. J. Mol. Biol. 103, 227-249. doi: 10.1016/0022-2836(76)90311-9

Warshel, A., Sharma, P. K., Kato, M., and Parson, W. W. (2006). Modeling electrostatic effects in proteins. Biochim. Biophys. Acta 1764, 1647-1676. doi: 10.1016/j.bbapap.2006.08.007

Young, T. E., and Babbitt, B. W. (1983). Electrochemical study of the oxidation of.alpha.-methyldopamine,.alpha.-methylnoradrenaline, and dopamine. J. Org. Chem. 48, 562-566. doi: 10.1021/jo00152a029

Conflict of Interest Statement: The authors declare that the research was conducted in the absence of any commercial or financial relationships that could be construed as a potential conflict of interest.

Copyright (c) 2018 Umek, Geršak, Vintar, Šoštarič and Mavri. This is an open-access article distributed under the terms of the Creative Commons Attribution License (CC $B Y)$. The use, distribution or reproduction in other forums is permitted, provided the original author(s) and the copyright owner(s) are credited and that the original publication in this journal is cited, in accordance with accepted academic practice. No use, distribution or reproduction is permitted which does not comply with these terms. 